\title{
IoT Based Energy-Efficient Data Aggregation Wireless Sensor Network in Agriculture: A Review
}

\author{
Vijay Nandal, Dr. Sunita Dahiya \\ Assistant Professor \\ Deenbandhu Chhotu Ram University Of Science And Technology, Murthal, Haryana
}

\begin{abstract}
:
Sensor nodes generate Wireless Sensor Networks (WSNs), these networks have considerable application in the areas of habitat safety, disaster management, surveillance in defense, security \& many more areas. WSNs are compact in size, with short battery power \& additionally their processing capabilities are low. This restriction of battery power makes them vulnerably faulty. In order to save this limited power, redundant data must be stored inside the sensor node during aggregation which will result in a reduction power dissipation associated with the sending of unnecessary data. By aggregating data, we can control energy consumption by reducing redundancy. Data aggregation is a really effective technique for WSN. In this paper we discuss the aggregation of data and their complex energy-efficient approach used for data aggregation in WSN. This paper highlights the latest innovations in WSNs vital for the research in agricultural domain, further we present their classification \& did a comparative analysis of the discussed protocols, the nomenclature of energy saving \& harvesting strategies used in agricultural monitoring. Further it discuss the difficulties and drawbacks of WSNs in context of agriculture, The presented comparative study will helpful in increasing number of data processing opportunities available through the Internet of Things (IoT).
\end{abstract}

Keywords:

Wireless Communication Technology; WSN; Energy-Efficient, Data Aggregation; IoT.

Article Received: 18 October 2020, Revised: 3 November 2020, Accepted: 24 December 2020

\section{Introduction}

The WSN emerged in 1998, from the dream of the Smartdust project which needed sensing and communication skills in the cubic millimeter order. The Sensor Node, which is a basic component of the WSN, consists of the device Sensing, Computing and Wireless Communication. These have been extended to different fields, such as Smart Cities, Smart Buildings and monitoring systems for the climate. Environmental surveillance systems deploy either small-scale nodes or large-scale networks to track natural phenomena in remote areas. This offers solutions which are economically sustainable and effective for a wide range of applications as health tracking, environmental \& animal tracking as well as tracking of various defense activities. WSN is a state of the art technology that combines sensor awareness, automation control digital network transmission data storage and information processing. It also uses different protocols to make it possible for IoT to grow faster [1]. The significant technological advancement in field of communication, computing and sensing leads to the development of small, efficient $\&$ less power consuming sensor nodes. This led to the realization that in the present times it can cater for several applications of extreme importance leading to a safe and more comfortable life which requires the automation and optimization of different processes based on intelligent physical phenomenon sensing. There are various sensors, processors and RF modules (Radio frequency) for battery-powered WSNs which help them to track a plethora of environments in order of achieving reliable data of the field [2]. Sensor nodes ' capabilities for sensing, storage, processing, and communication have therefore continuously increased. WSNs were used in various applications, including defense forces, agriculture, sports, pharmacy and other industries. The WSN's implementations in agriculture are very advantageous in improving agricultural productivity which in result reduces the farmer's 
burden to a great extent [3]. Many of the farming practices can be done precisely with the aid of WSNs, resulting in yield production and minimize the agricultural costs. The sensor nodes can be deployed for calculating various soil and atmospheric parameters.

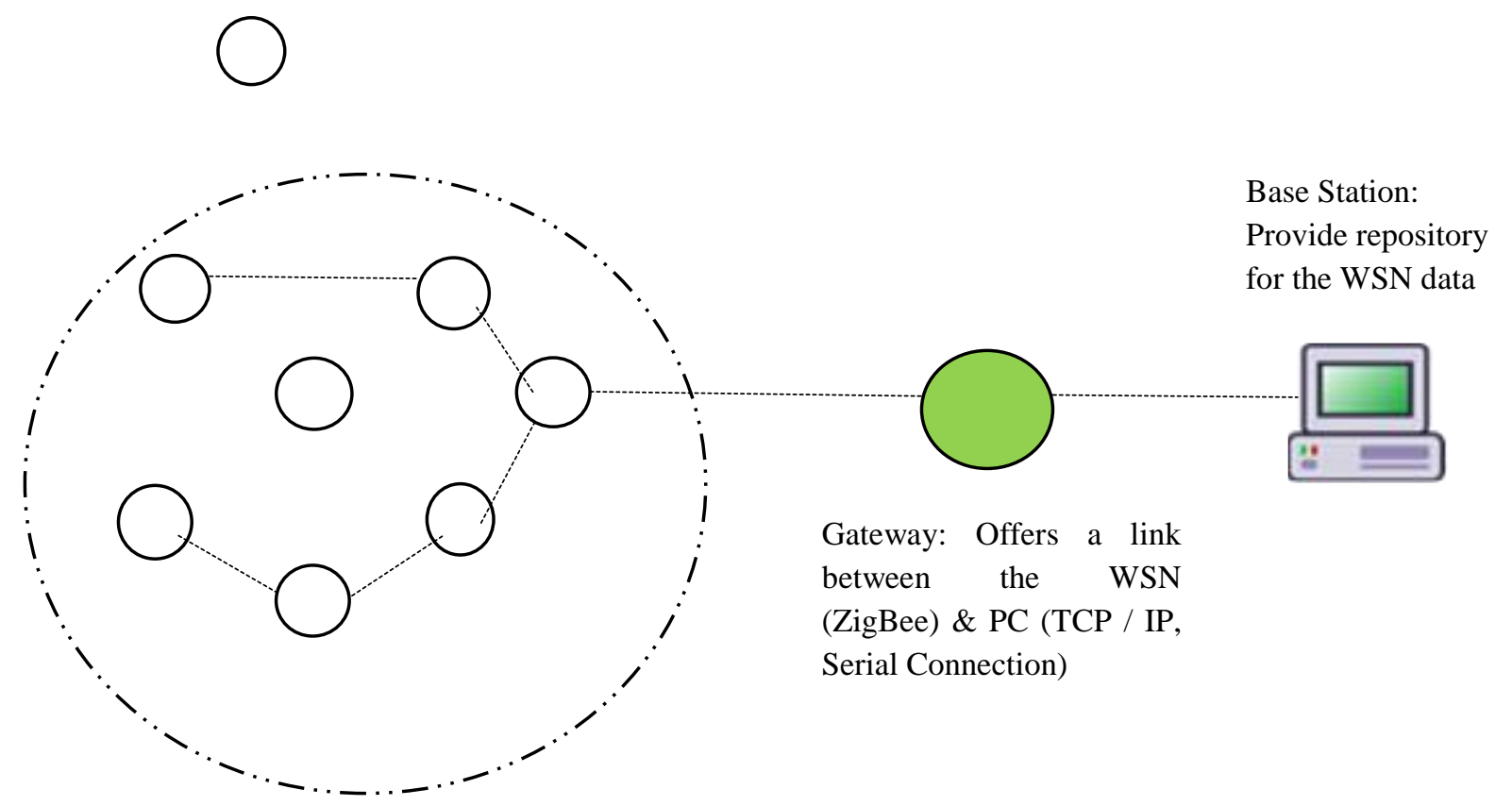

Fig. 1. A Wireless Sensor Network [2].

Precision farming refers to identifying, gathering and transmitting data for decision making at a control station and activating it according to the decision. The distribution of each crop is determined by climatic conditions, soil fertility. Agriculture is difficult, because they are not deterministic. The authors have therefore combined wireless sensor networks (WSN) with modern agro ideas to tackle node failure with a suggested routing mechanism. However, the agricultural implementation of WSNs has been hampered by some challenges, such as deciding optimal deployment [5] schemes, routing protocols, measurement times, energy efficiency, expense, scalability, fault tolerance and communication range. Scattered installation of sensor nodes with a long data collection time, for example, will help extend the life of the network.

Some considerations, however, can challenge the distribution area selection. When the agricultural field encounters several obstacles, as a result of signal attenuation, the contact connection may be compromised or lost. The sensor nodes are supplied from the battery in WSNs and thus prevent the deployment position from connecting to the main supply. In view of their limited battery capacity, it is important for WSNs to $[6,7]$ reduce power depletion and extend battery life. Although there has been a steady increase in the application of WSNs over the years, battery production not gets advanced at the same rate as a result these networks are primarily constrained due to their battery life. This paper is directed towards energy management among the aforementioned problems and highlights techniques for energy-efficient production that can be used in agriculture.

The base station is connected by unmanned aerial vehicles or drones to meet PA requirements; a mobile data link service may be created for solving the problems such as the elongated distances between the farm\& base stations. This link enables the sensor nodes for transmitting data within wide area of agricultural field to the base station. This approach, however, 
is constrained by WSN's quality of service. For efficient agricultural monitoring, the criteria to be met by implementing a WSN apply to each system's [5] level issues (i.e. unattended service, overall network existence, adaptability or even self-configurability of functionalities and protocols) and end-user needs (i.e. reliability and robustness of communication, user-friendly, scalable and efficient graphical user interfaces). PA (Precision Agriculture) varies in the sense that this method correctly defines differences for traditional farming and relates [4] spatial data for managerial operations. PA includes five phases: (i) compilation of data, (ii) evaluation, (iii) analysis of data, (iv) field precise operation, and (v) evaluation. These may help to make decisions on applications for irrigation, fertilizer, and pesticides. The WSNs can also be used for applications such as detection of intruders, insect detection, prediction of plant disease, fire detection, automation of irrigation, etc. Some of India's current and past agricultural ventures are Agrisens, mKRISHI, Agrosense etc. Certain important issues that can be addressed using WSNs include planting mushrooms and monitoring cattle.

The review is framed as: Section 2 discuss about the WSN protocols, Section 3 provides Performance comparison of protocols for wireless communication. The section 4 highlights the WSN protocols on energy conservation data aggregation, further it deals with the detailed study and comparisons of structured \& structure free WSN protocols. Later in section 5 we did a comparative study of precise farming techniques in WSN. The Section 6 offers a review of literature associated with WSN protocols \& techniques for agriculture, next section highlights the research gap and lastly in Section 8 we concluded the paper with future prospect of the domain.

\section{2 .The Protocols in Wireless Sensor Network}

This segment of our study first discuss about the various protocols and standards used in WSN and later compares them to determine the most suitable system as consumption of power, range of contact [8] \& various other parameters, all columns provides these protocol's challenges \& solution proposed for them.

\section{Wireless ZigBee protocol}

This is counted among the most suited protocols used in various agriculture applications. This protocol is found very suitable for the PA (Precision Agriculture) applications as irrigation control, managing water quality due to its low duty cycle [9], and regulate fertilizers and pesticides control, all requiring cyclic information update. When using XBee Series 2 the Agricultural sensor nodes which communicate with a long distanced (Hundred meter) router or coordinator node based on this technology for indoor (Greenhouses) conditions. Furthermore, ZigBee can reduce contact distance to a maximum of 30 meters. The number of sensor nodes \& routers deployed under monitoring will be broadened by covering the whole area of the field. For PA, ZigBee was used in some research such as; ZigBee was used at the base station to study the impact strength of signal on antenna height, node size, and density of the leaf [10, 11]. Even used in a grazing field was focused on cattle location ZigBee WSN. Rather than necessity of additional hardware, for measuring distance, ZigBee depends on the indication of connection quality. At low power consumption and minimum cost, the ZigBee protocol achieves cattle location $[31,32,34]$. The greenhouse climate's key parameters (temperature, humidity, solar radiation andCO2) are assumed to provide healthy energysaving plant growth [12] of $22 \%$ and water consumption is 33 per cent. The ZigBee and General Packet Radio Service (GPRS)/ Global System Mobile Communication (GSM) systems have been implemented for tracking and regulating greenhouse environment. 


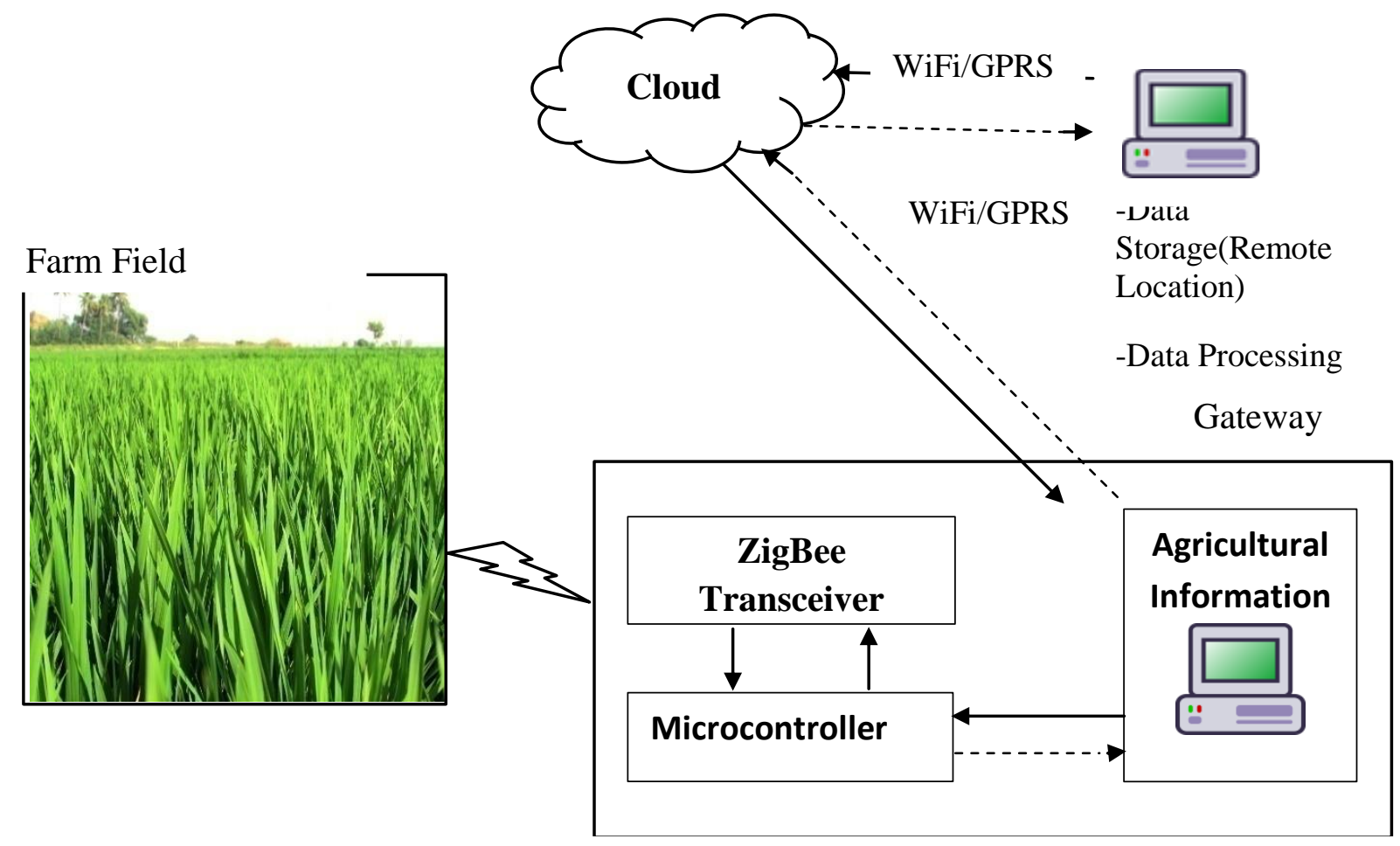

Fig. 2. A general setup of ZigBee protocol in agriculture [10]

Furthermore, the ZigBee wireless protocol was used for animal behavior control (e.g. walking, to sleep, to lie and to stand). It has also been implemented to address the issues of unreliability\& high power efficiency of ad-hoc WSN cells [13] which are implemented to save energy by alternating between the active and sleeping states. This allows minimizing consumption of power and boosting the battery life of sensor nodes. Actually this is used in pastures and barns for smart beehives, orange orchards, cow dairy protection surveillance systems, irrigation control, greenhouse and livestock tracking. The ZigBee protocol has been used as a universal standard for WSNs in many agricultural applications due to its [14] reduced consumption of power, cost, self-forming features $\&$ a decent contact range.

\subsection{Bluetooth (BT) Wireless Protocol}

This protocol was used for a small distance up to $10 \mathrm{~m}$ to connect mobile and portable devices, such as laptops, for communication. The BT has been used to satisfy multilevel agricultural requirements thanks to its omnipresence and incorporation in most mobile devices. The proposed model for irrigation practices was designed for production boost of the field \& to conserve water $[15,16]$. The framework for irrigation proposed to collect real-time field information using BT's Wireless Communications Protocol. For BT-based greenhouses many software and hardware have been developed for controlling relative humidity and temperature. Using an integrated control method [17], in greenhouses, the BT module controlled the irrigation system. The outcome of the calculation for water usage \& energy based on an optimized control method using BT technology was improved by 90 percent was compared to the conventional (i.e. timer control approach) system. BT based smartphones was used in various agricultural applications [18], for example, Irrigation systems supervision, soil monitoring, weather conditions \& fertilizer $\&$ pesticide management.

\subsection{WiFi Wireless Protocol}


This is a wireless technology widely used in compact appliances where tablets, desktops and laptops are included. For indoor and outdoor settings, WiFi has an acceptable contact gap of about $20 \mathrm{~m}$ and $100 \mathrm{~m}$ respectively [19]. The WiFi expands the various PA framework architectures by linking several system types to ad hoc network.

The wireless technologies like $3 \mathrm{G} \& \mathrm{WiFi}$ were used for estimating agricultural mobile phone applications. It also uses distant accessible services \&brief messages to monitor and control secured crops. For agricultural monitoring, a smart WSN with Wi-Fi (IEEE 802.11 g) is suggested, which comprises of three nodes: router, sensor and server [20]. The greenhouse or agricultural field climate conditions are monitored; these include air pressure, water, humidity, soil moisture, light and temperature. WiFi needs a lot of power, communication delay and huge data payload $[21,46]$. Despite the reality that Wi-Fi protocol avoid data loss by adopting techniques for data redundancy; thus for agricultural applications WiFi technology is not preferable. Therefore, this can't be used for multihope applications \& is determined byuser statistics\& strength of the signal, rendering it undesirable for WSNs in agriculture [22, 44]. In fact, the WiFi nodes are listening all the time, thereby increasing the power consumption.

\subsection{GPRS Based Network}

The GPRS (General Packet Radio Service) services for mobiles are based on GSM driven data transmission. It often encounters throughputs, variable delays \& the number of users using the same communication channels and facilities is based on this framework. Gutiérrez et al. [23] developed an automated knowledge based crop irrigation network gathered from soil moisture\& temperature sensors mounted in the plant root zone using the GPRS module and WSN, and this system was considered cheap and realistic solution to improve quality of water at PA. Soil moisture measurement tested a form of drip irrigation. It also developed a server managing data based prototype along with WSN-GPRS gateway [24]. The interface of WSN-GPRS is used as a WSN-GPRS bridge from which data is forwarded to a data center; Hellín-Navarro et al. [25] it is installed with GPRS for calculating and transmitting various parameters' information as of soil, plants and atmospheres of different wireless nodes. Wireless nodes have full flexibility, thanks to their independence and use of solar energy. For further research, various sensors can transmit information via tablets, mobile phones or computers via a GPRS network to a remote location. All agricultural sensors interfaced with sensor board to collect information on agriculture. This information is forwarded via the GPRS monitor that is based on a mobile GSM / GPRS network, to the remote server for further revision.

\subsection{LoRa (Long Range Radio) Protocol}

The LoRa Alliance introduces LoRa protocol as a stack of low-power protocol indoor transmission and broad networking technologies related to the Internet of Things (IoT)[33].The basic architecture of a LoRa network, WAN is composed of end devices of LoRa protocol [26], The gateways of this protocol\& a server for its network. The end node of LoRa links to gateways using LoRa for LoRa WAN. LoRa end user gateways send raw LoRa WAN packets, typically 3G or Ethernet, for a high backhaul-based LoRa network server. While LoRa gateways operate with the LoRa network server as bidirectional Adapter or Protocol [36]. It is the role of a server of LoRa network in this situation to interpret the packets of data disseminated by LoRa apps\& to generate frames which are returned to the devices. It provides a two-way streak approach which suits machine-to-machine (M2 M) WiFi [38] protocol. It provides a cheap approach for connecting mobile devices or batteries operating on a network or server. This protocol has been used for bee colonies surveillance in rural areas \& for establishing remote contact point of bee node with a central server [27]. Soil humidity, temperature 
and light intensity were also controlled in greenhouses using various sensors, the LoRa wireless protocol and microcontrollers. To create a star network topology, LoRa gateway collects LoRa node's data\& can connect the long communication spectrum and high scalability to a cloud server [37].

This is now a days has been used at agricultural projects created by Libelium Company (Zaragoza, Spain),e.g. improvement of production of kiwi using a system for smart irrigation (Italy), climatic controlled tobacco crop production (Italy), conservation of water by smart irrigation methods (Barcelona), controlling vineyards (Spain) and tracking vineyard affecting diseases (Switzerland).

\subsection{SigFox Protocol}

For applications with low data rates, it is ultranarrowband cellular wireless network which makes it suitable for IoT communication systems. The SigFox has been used in a range of apps include telecommunications, defense, the Internet, broadband and television [28]. During the summer, this network is used to create a geolocation device for animals in mountain pastures. It suggests a program for assisting farmers to track \& increase their cattle production. The value of an energy consumption analysis [29] was particularly outlined when animal herds located at high mountainous areas.

\section{Performance based comparative study for WSN protocols}

The comparison \& discussion of these protocols \& technologies on various factors as communication range, complexity of the network, power consumption, cost, data, and other factors were done in table 1 . With selecting deployment range the problems posed in agricultural applications may be defined. For example, the transmitted sensor node signal is ameliorated by dividing the region of [30] agriculture with Barriers. Consumption in power with agricultural applications found as further restriction in WSN architecture.

This protocol was designed to work at low power \& within proper communication range as well. Consequently, the comparison of power consumption \& communication distance in above listed technologies was pictorially shown below in fig. $1 \&$ fig. 2 respectively.

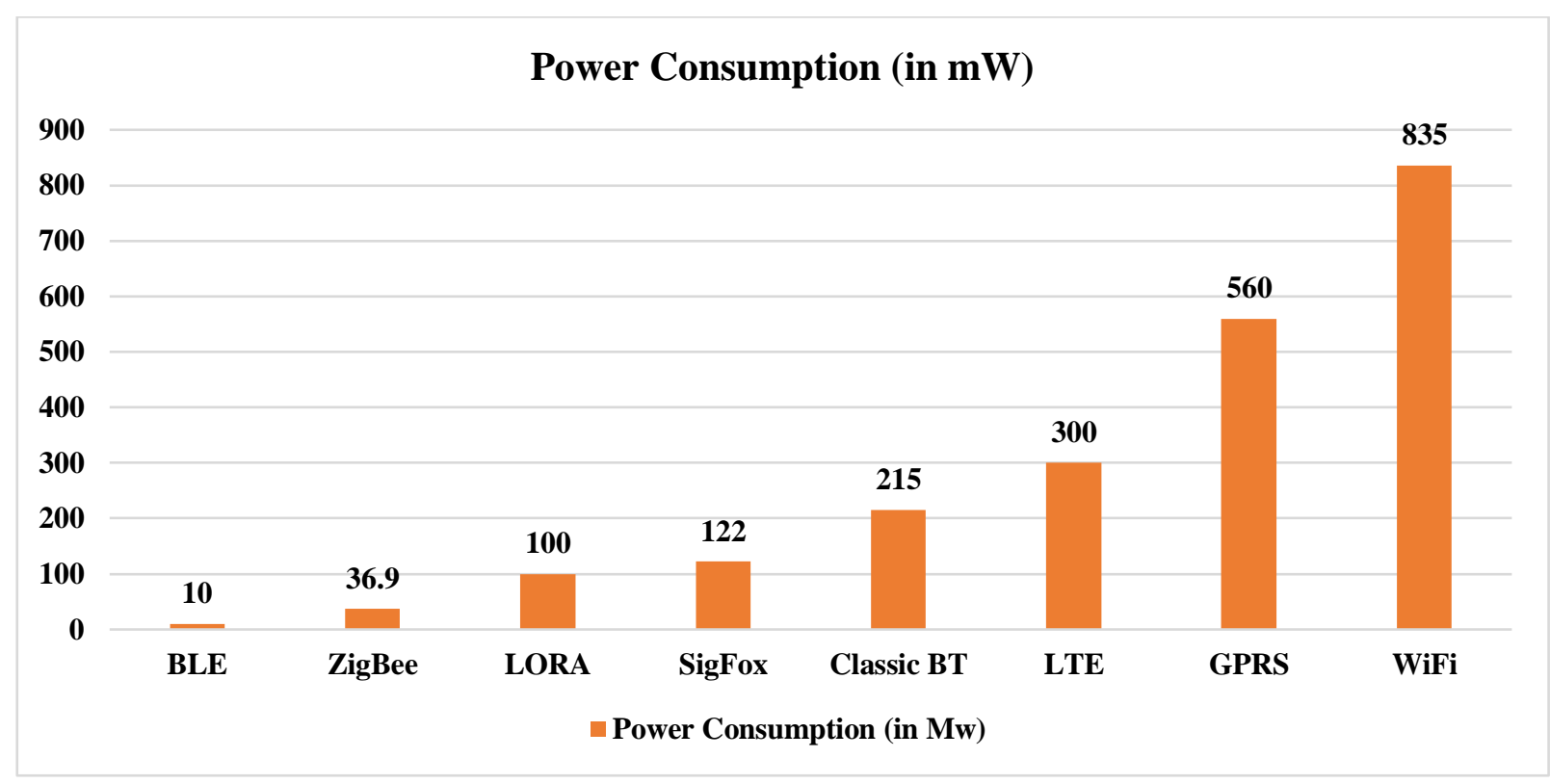

Fig. 3. Comparison of power consumption [68] 


\section{Communication Distance (m)}

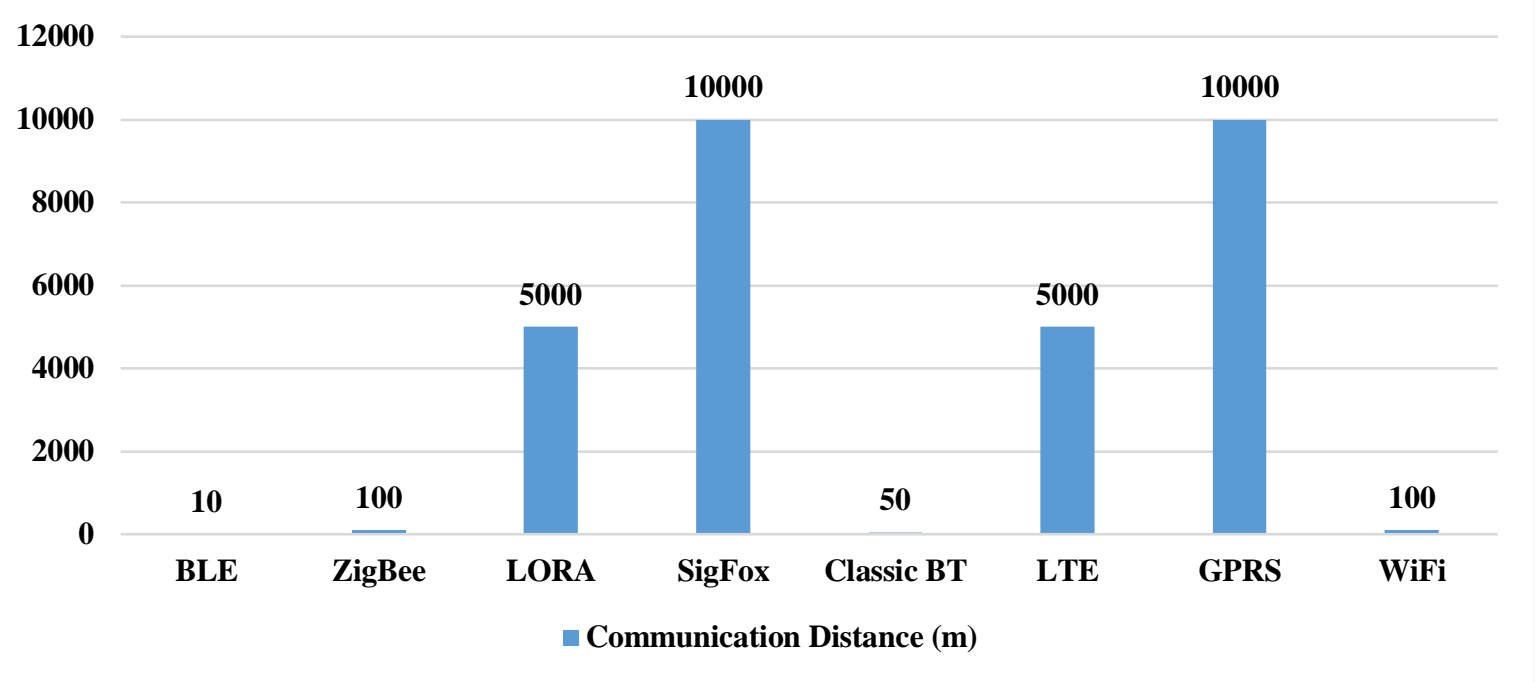

Fig. 4. Comparison of communication Distance [68]

The wireless protocols considered for the case of agricultural applications improve the agricultural area in terms of precision. Using sensors, actuators, processors, wireless transceivers and other information technology, PA will allow manufacturers computerize site-specific Automated Agriculture Management. Precision irrigation is often considered to maximize the efficiency of irrigation because of its potential to control optimal water and irrigation period. In testing, water savings was found $50 \%$ \& $90 \%$ (Using Bluetooth), and of $33 \% \& 90 \%$ (Using ZigBee) were obtained for precision systems for irrigation as compared with conventional systems for irrigation [50,51], respectively. By using the wireless protocol ZigBee, animal activities such as lying, standing, feeding, walking and other forms have been tracked. The authors found that compared to results from similar studies, laying down and grazing could be enhanced by 83.5 percent. In a further study which adopted a proposed wireless protocol-dependent algorithm $[39,40]$, the proposed algorithm for monitoring honey bee and the environmental and agricultural aspects was expected to have an accuracy rate of
95.4 percent. With energy efficiencies of 2.05 to 8.21 per cent \& energy savings between 0.71 and 6.46 per cent, ZigBee-based irrigation system automation saved system costs between 1.24 per cent and 6.72 per cent compared to total water user association's costs. The three types of irrigation systems were enabled by the proposed model used in [35] Smartphone interface (GSM \& Bluetooth-based). Factors of effectiveness improved by 90 percent in the form of underground drip, and by 85 percent and 75 percent in the forms of high and low pressure overhead sprinklers. Water droplets were penetrated to measure drift and evaporation before surface. The $3 \mathrm{G}$ technology used by Libelium was introduced using Wireless sensor waspmote devices to track Northwest Spain vineyards [57]. Phytosanitary materials, such as fertilizers and fungicides; improved yields increased by $15 \%$ \& decreased $20 \%$ with PA. LoRa deemed to control $90 \%$ power output in agricultural environments [8]. The pumping and water costs of the common irrigation systems were cut by 30 per cent in green areas with SigFox [58].

Table 1 Comparative Chart of Various Technologies for Wireless Communication [68]

\begin{tabular}{|l|l|l|l|l|l|l|l|}
\hline Parameters & LORA & BLE & ZigBee & GPRS & Wi-Fi & SigFox & $\begin{array}{l}\text { Classic } \\
\text { BT }\end{array}$ \\
\hline
\end{tabular}




\begin{tabular}{|c|c|c|c|c|c|c|c|}
\hline Standard & $\begin{array}{l}\text { IEEE } \\
802.15 .4 \mathrm{~g}\end{array}$ & $\begin{array}{l}\text { IEEE } \\
802.15 .1\end{array}$ & $\begin{array}{l}\text { IEEE } \\
802.15 .4\end{array}$ & $\mathrm{~N} / \mathrm{A}$ & $\begin{array}{l}\text { IEEE } \\
802.15 .4\end{array}$ & $\begin{array}{l}\text { IEEE } \\
802.15 .4 \\
\mathrm{~g}\end{array}$ & $\begin{array}{l}\text { IEEE } \\
802.15 .1\end{array}$ \\
\hline Spreading & CSSS & FHSS & DSSS & $\begin{array}{l}\text { TDMA, } \\
\text { DSSS }\end{array}$ & $\begin{array}{l}\text { MC- } \\
\text { DSSS } \\
\text { CCK }\end{array}$ & N/A & FHSS \\
\hline $\begin{array}{l}\text { Channel } \\
\text { Bandwidth }\end{array}$ & $\begin{array}{l}<500 \\
\mathrm{KHZ}\end{array}$ & $1 \mathrm{MHZ}$ & $2 \mathrm{MHZ}$ & $200 \mathrm{KHZ}$ & $22 \mathrm{MHZ}$ & $<100 \mathrm{HZ}$ & $1 \mathrm{MHZ}$ \\
\hline $\begin{array}{l}\text { No. of RF } \\
\text { channel }\end{array}$ & $\begin{array}{l}10 \text { in } \mathrm{Eu}, \\
8 \text { in US }\end{array}$ & 40 & $1,10 \& 16$ & 124 & 11 & 360 & 79 \\
\hline Data Rate & $50 \mathrm{kbps}$ & $1 \mathrm{mbps}$ & $\begin{array}{l}20, \quad 40 \& \& \\
250 \mathrm{kbps}\end{array}$ & $\begin{array}{l}\text { Up to } 170 \\
\text { kbps }\end{array}$ & $\begin{array}{l}11-54 \& \\
150 \mathrm{mbps}\end{array}$ & $100 \mathrm{bps}$ & $1-3 \mathrm{mbps}$ \\
\hline Latency & N/A & $6 \mathrm{~ms}$ & $20-30 \mathrm{~ms}$ & $<1 \mathrm{~s}$ & $50 \mathrm{~ms}$ & N/A & $100 \mathrm{~ms}$ \\
\hline $\begin{array}{l}\text { Frequency } \\
\text { Band }\end{array}$ & $\begin{array}{l}869 / 915 \\
\text { MHZ }\end{array}$ & $2.4 \mathrm{GHZ}$ & $\begin{array}{lr}869 / & 915 \\
\text { MHZ\& } & 2.4 \\
\text { GHZ } & \\
\end{array}$ & $\begin{array}{l}900-1800 \\
\text { MHZ }\end{array}$ & $2.4 \mathrm{GHZ}$ & $\begin{array}{l}\text { 868/915 } \\
\text { MHZ }\end{array}$ & $2.4 \mathrm{GHZ}$ \\
\hline $\begin{array}{l}\text { Modulation } \\
\text { Type }\end{array}$ & GFSK & GMSK & $\begin{array}{l}\text { OQPSK } \quad / \\
\text { BPSK }\end{array}$ & $\begin{array}{ll}\text { 8PSK } & \text { / } \\
\text { GMSK } & \end{array}$ & $\begin{array}{l}\text { OQPSK / } \\
\text { BPSK }\end{array}$ & $\begin{array}{l}\text { GFSK } \\
\text { (DL), } \\
\text { DBPSK } \\
\text { (UL) }\end{array}$ & $\begin{array}{l}\text { DQPSK, } \\
\text { DPSK \& } \\
\text { GPSK }\end{array}$ \\
\hline $\begin{array}{l}\text { Power } \\
\text { consumptio } \\
\mathbf{n} \text { in } \mathbf{T x} \\
\text { mode }\end{array}$ & $\begin{array}{l}\text { Low } \\
100 \mathrm{~mW}\end{array}$ & $\begin{array}{l}\text { Ultra Low } \\
10 \mathrm{Mw}\end{array}$ & $\begin{array}{l}\text { Low } \\
36.9 \mathrm{~mW}\end{array}$ & $\begin{array}{l}\text { Medium } \\
560 \mathrm{~mW}\end{array}$ & $\begin{array}{l}\text { High } \\
835 \mathrm{~mW}\end{array}$ & $\begin{array}{l}\text { Low } \\
122 \mathrm{~mW}\end{array}$ & $\begin{array}{l}\text { Medium } \\
215 \mathrm{~mW}\end{array}$ \\
\hline $\begin{array}{l}\text { Communica } \\
\text { tion Range }\end{array}$ & $5 \mathrm{~km}$ & $10 \mathrm{~m}$ & $100 \mathrm{~m}$ & $1-10 \mathrm{~km}$ & $100 \mathrm{~m}$ & $10 \mathrm{~km}$ & $10-50 \mathrm{~m}$ \\
\hline $\begin{array}{l}\text { Network } \\
\text { Size (nodes } \\
\text { per BS) }\end{array}$ & 10,000 & $\begin{array}{l}\text { Limited } \\
\text { by } \\
\text { Applicatio } \\
\mathrm{n}\end{array}$ & 6500 & 1000 & 32 & 1000,000 & 8 \\
\hline Cost & Low & Low & Low & Medium & High & Low & Low \\
\hline $\begin{array}{l}\text { Security } \\
\text { Capability }\end{array}$ & $\begin{array}{ll}\text { AES } & 128 \\
b & \end{array}$ & $\begin{array}{l}64 \text { or } 128 \\
\text { bits AES }\end{array}$ & $\begin{array}{ll}128 & \text { bits } \\
\text { AES } & \end{array}$ & $\begin{array}{l}\text { GEA, } \\
\text { MS SGSN } \\
\text { MS HOST }\end{array}$ & $\begin{array}{ll}128 & \text { bits } \\
\text { AES } & \end{array}$ & $\begin{array}{l}\text { Encrypti } \\
\text { on not } \\
\text { supporte } \\
d\end{array}$ & $\begin{array}{l}64 \text { or } 128 \\
\text { bits AES }\end{array}$ \\
\hline Application & $\begin{array}{l}\text { Agricultu } \\
\text { re, Smart } \\
\text { grid, } \\
\text { Environm } \\
\text { ent \& } \\
\text { lighting } \\
\text { control }\end{array}$ & WPANs & $\begin{array}{l}\text { WPANs, } \\
\text { WSNs, } \\
\text { Agriculture }\end{array}$ & $\begin{array}{l}\text { AMI, } \\
\text { HAN, } \\
\text { Demand } \\
\text { Response }\end{array}$ & WLANs & $\begin{array}{l}\text { Agricultu } \\
\text { re, } \\
\text { Automoti } \\
\text { ve, } \\
\text { buildings } \\
\& \text { Consu } \\
\text { mer } \\
\text { Electroni } \\
\text { cs }\end{array}$ & WPANs \\
\hline $\begin{array}{l}\text { Network } \\
\text { Topologies }\end{array}$ & $\begin{array}{l}\text { Star or } \\
\text { Stars }\end{array}$ & Star, Bus & $\begin{array}{l}\text { P2P, Tree, } \\
\text { Star. Mesh }\end{array}$ & $\begin{array}{l}\text { Cellular } \\
\text { system }\end{array}$ & $\begin{array}{l}\text { Point to } \\
\text { hub }\end{array}$ & Star & $\begin{array}{l}\text { Scatter } \\
\text { net }\end{array}$ \\
\hline Limitations & $\begin{array}{l}\text { Network } \\
\text { size } \\
\text { (Scalibilit }\end{array}$ & $\begin{array}{l}\text { Short } \\
\text { communic } \\
\text { ation }\end{array}$ & $\begin{array}{l}\begin{array}{l}\text { Line } \\
\text { sight }\end{array} \\
\text { (LOS) }\end{array}$ & $\begin{array}{l}\text { Power } \\
\text { consumpti } \\
\text { on } \\
\end{array}$ & $\begin{array}{l}\text { High } \\
\text { power } \\
\text { consumpt }\end{array}$ & $\begin{array}{l}\text { Low data } \\
\text { rates }\end{array}$ & $\begin{array}{l}\text { Short } \\
\text { communi } \\
\text { cation }\end{array}$ \\
\hline
\end{tabular}




\begin{tabular}{|c|c|c|c|c|c|c|c|}
\hline & & $\begin{array}{l}\text { y), Data } \\
\text { rate \& } \\
\text { Message } \\
\text { capacity }\end{array}$ & range & $\begin{array}{l}\text { between } \\
\text { the sensor } \\
\text { node \& the } \\
\text { coordinator } \\
\text { node must } \\
\text { be } \\
\text { available }\end{array}$ & problem & $\begin{array}{ll}\text { ion \& } \\
\text { long } \\
\text { acess } \\
\text { time } \\
(13.74 \mathrm{~s})\end{array}$ & range \\
\hline
\end{tabular}

As per the discussion and the empirical findings provided in Table 1. Small size, low latency (for ZigBee), quick network deployment, accessibility, scalability, reduced power use, network capacity, communication range, LoRa \& ZigBee wireless protocols were suited best wireless protocols in applications for agriculture.

The previous survey of various agrarian technologies showed The PA can be accomplished for various wireless protocols in Water saving conditions, animal behavior, performance, power efficiency and system cost reduction [42, 43]. Agriculture can therefore be constructed on the basis of compared with the traditional agricultural systems, agricultural automation systems.

\section{WSN Protocols on Energy Conservation Data Aggregation}

The WSNs are used primarily for the collecting and analysis of data. The collection of data is characterized as organized integration of sensed multi-sensor data that is eventually sent to base station for processing. Nevertheless, the data produced by adjoining sensor nodes remains superfluous \& very interrelated. In these situations, sensor nodes may send data to local collector or specified head, combining all sensor nodes' data residing in its contact \& transmitting the succinct packet accessible at base station, reduces all packet transfers and hence saves bandwidth \& money which may achieved by aggregating the data. Data aggregation [53] is described as governing concept for integrating data sensed from various sensor nodes with decreased redundancy, \&facilitates base station with the aggregate data. The Protocols for data aggregation can be divided in two groups as mentioned in the literature: structured \& structurefree [54] as shown in the Fig. below,

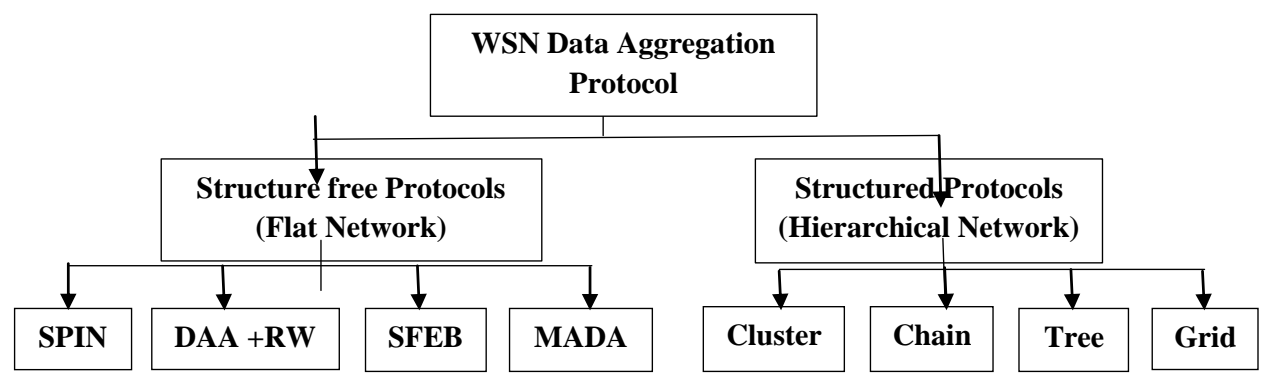

Fig. 5 Energy conservation data aggregation protocols of WSN

\section{WSN Structure Free Protocols for data aggregation}

Each sensor node deployed in a particular region for structure-free networks has identical responsibilities \& carries the type of battery is almost identical. The data centric routing is used for achieving Data aggregation in such type of networks, where sensor nodes continuously receiving a question message from base station. We define these protocols in Table 3, and outline their key features, pros and cons.

\section{SPIN (Sensor protocol for information via negotiation)}

The SPIN protocol family relies on the two basic ideas. Firstly, sensor systems need to communicate with each other on the data they 
already have and on the data they are planning to obtain for successful operation and energy conservation. Switching sensor data can be a costly network operation, but there is no need to share sensor data. Secondly, network nodes need to monitor and adjust changes in their own energy resources to extend the operating life of the system [55]. SPIN is a structured protocol for disseminating information that is appropriate for WSN based on metadata.

\section{DAA + RW (Data-aware anycast \& randomized waiting)}

Fan et al suggested a structurally free event-driven reporting scheme (DAA+RW) for data aggregation in WSN. An event detected by sensor node first sends any cast RTS to the base station for determining the next hop node for the transmission of event data. The sensor node that collects this RTS will be the candidate for hop next time. To achieve greater aggregation performance, sensor nodes which have the similar Responding to CTS is given priority for event data for transmission or lies near the base station. Additionally, a randomized waiting scheme is set up for reducing overall transmission counts, such that every sensor node is required to report the event data will begin transmission after random wait \& possible aggregation is triggered if a node near to base station is waiting for long.

\section{SFEBDA (Structure-free and energy- balanced data aggregation)}

Chih-Min et al suggested that this is a two-phase protocol for WSN [56]. The first phase deals with an event to occur, such sensor nodes are selected on the basis of their role as primary and secondary aggregators (PA, SA respectively) \& for the next phase, assumed a pair as PA / SA pair, where sensor node close to the base station is referred as aggregator \& second as forwarding node for the early aggregation \& selection of the forwarding nodes. Those aggregators return the received packets to base station in the second phase.

\section{MADA (Multi-agent data aggregation)}

The protocol that operates randomly when a sensor node senses important information; must include its neighbors in the aggregation of the most relevant details to be sent to the base station was introduced by Sardouk et al [57]. In this every sensor node determines whether to be the part of data aggregation process or not based on the specific factor of participation decided by the different parameters as distance, position, criticality, information and energy.

Table 2. Tabular Review of structure free aggregation data protocols

\begin{tabular}{|l|l|l|l|}
\hline Protocol & $\begin{array}{l}\text { Selection of Aggregation } \\
\text { Head }\end{array}$ & Advantage & Disadvantage \\
\hline SPIN [73] & Based on descriptors & $\begin{array}{l}\text { Each sensor node needs their } \\
\text { individual hop neighbors to be } \\
\text { aware of only topological } \\
\text { changes. }\end{array}$ & $\begin{array}{l}\text { Inability of data delivery } \\
\text { guarantee. }\end{array}$ \\
\hline $\begin{array}{l}\text { DAA + RW } \\
\text { [74] }\end{array}$ & $\begin{array}{l}\text { Aggregation depends on } \\
\text { the detection of event }\end{array}$ & $\begin{array}{l}\text { Every node with similar } \\
\text { reporting event data or closer } \\
\text { to base station can start } \\
\text { transmission with higher } \\
\text { priority. }\end{array}$ & $\begin{array}{l}\text { Poor aggregation } \\
\text { randomized due to short } \\
\text { chosen by the sensor } \\
\text { nodes near the base } \\
\text { station }\end{array}$ \\
\hline SFEBDA [75] & $\begin{array}{l}\text { Primary and secondary } \\
\text { aggregator (PA/SA) pair } \\
\text { based on their location }\end{array}$ & $\begin{array}{l}\text { Efficient collection of data } \\
\text { and efficient energy using } \\
\text { aggregation process in two } \\
\text { phases with dynamic }\end{array}$ & $\begin{array}{l}\text { Overhead computation } \\
\text { when choosing dynamic } \\
\text { aggregator } \\
\text { network holes }\end{array}$ \\
\hline
\end{tabular}




\begin{tabular}{|l|l|l|l|}
\hline & & aggregator selection method & \\
\hline MADA [76] & Multi agent- structure free & $\begin{array}{l}\text { Cooperating agents remove } \\
\text { the inter- repetition of sensor } \\
\text { nodes and merge the collected } \\
\text { information from a processing } \\
\text { session into one message }\end{array}$ & $\begin{array}{l}\text { Aggregator node } \\
\text { selected using event } \\
\text { detection }\end{array}$ \\
& & & \\
\hline
\end{tabular}

\section{WSN Structured Protocols of data aggregation}

\section{Cluster}

The network is split into subgroups in a clusterbased system, and each subgroup is called a cluster. There are several sensor nodes in each cluster where one node is called $\mathrm{CH}$ (Cluster Center). They are allocated to forward data to the sink from their cluster nodes and typically regard the masters \& sensor nodes as slaves, this structure (master/slave) allows a close traffic control, as no node may be transmitted beyond the cluster and no communication with the slaves is permitted but via the master.

\section{Chain}

Lindsey et al. suggested a chain-based information aggregation protocol for Sensor Information Systems (PEGASIS)[58]. The PEGASIS nodes are organized into a linear data aggregation chain. The nodes can form a chain by using a greedy algorithm, or the sink will centrally evaluate the chain. Creation of the Greedy chain means that all the nodes have the skills of a global network. The creation of a chain is chosen as its counterpart in the sequence, starting with the furthest node from the sink and, at each stage, the closest neighbor of the node. A node collects data from one of its neighbors, uses its own data in every data collection round, and transmits the fused data along the chain to its neighbor. Basically the leader node near the head of the cluster transmits the aggregated data to the sink.

\section{Tree}

The sensor nodes are grouped in a tree-like structure, and the data are aggregated at intermediate nodes along the chain. Aggregation is accomplished in a tree-based system by constructing an aggregation tree which may be a minimum spanning tree, embedded in the sink, and the leaves are considered root nodes. Every node has a parent node with which to forward data. The data flow continues from the leaves ' nodes to the drain and in the parent's nodes.

\section{Grid}

A two data aggregation schemes have been suggested by Vaidhyanathan et al. [59]: Aggregation of grid-based data and aggregation of data in the network, as per area partitioning. Through grid-based data aggregation a group of sensor nodes through fixed regions of the wireless sensor network is allocated as data aggregators. In a specific grid the sensor nodes relay the data directly to that grid's data aggregator. In a specific grid the sensor nodes relay the data directly to that grid's data aggregator therefore, inside a grid the sensor nodes do not interact among one another. Aggregation of grid-based data is consistent with the nomadic settings as surveillance in defense \& forecasting of weather, in which adaptation of dynamic and mobile transition of events is required.

Table 3 Tabular Review of structured aggregation data protocols

\begin{tabular}{|l|l|l|l|l|}
\hline $\begin{array}{l}\text { Basic } \\
\text { framework }\end{array}$ & Protocol & Core Traits & Pros & Cons \\
\hline Cluster & LEACH & $\begin{array}{l}\text { Chooses sensor nodes as } \\
\text { cluster heads (CHs) at } \\
\text { random. }\end{array}$ & $\begin{array}{l}\text { Every node has the same } \\
\text { probability of becoming } \\
\text { the head of the cluster. }\end{array}$ & $\begin{array}{l}\text { There's a strong } \\
\text { possibility that a very } \\
\text { low }\end{array}$ \\
\hline
\end{tabular}




\begin{tabular}{|c|c|c|c|c|}
\hline & & $\begin{array}{l}\text { Adjusts this feature to } \\
\text { distribute the energy } \\
\text { charge in the network } \\
\text { evenly between the } \\
\text { sensors. }\end{array}$ & $\begin{array}{l}\text { Using TDMA prevents } \\
\text { CHs safe from unwanted } \\
\text { collisions }\end{array}$ & $\begin{array}{l}\text { will be picked as a } \\
\mathrm{CH} \text {. } \\
\text { Unable to guarantee } \\
\text { good distribution of } \\
\mathrm{CHs} \text {. } \\
\text { In their set, those } \\
\text { nodes have no } \mathrm{CH} \text {. }\end{array}$ \\
\hline Chain & $\begin{array}{l}\text { PEGASIS } \\
{[70]}\end{array}$ & $\begin{array}{l}\text { The Nodes are distributed } \\
\text { along a Greedy linear } \\
\text { chain method. }\end{array}$ & $\begin{array}{l}\text { The Energy charge is } \\
\text { evenly distributed, } \\
\text { Reduce overhead due to } \\
\text { dynamic cluster } \\
\text { formation, Reduces data } \\
\text { transmission numbers }\end{array}$ & $\begin{array}{l}\text { No problems of } \\
\text { surplus data. } \\
\text { Needs global } \\
\text { experience in which } \\
\text { all the nodes are at } \\
\text { the sink. } \\
\text { There is delay due to } \\
\text { formation of long } \\
\text { chains }\end{array}$ \\
\hline Tree & $\begin{array}{l}\text { EADAT } \\
{[71]}\end{array}$ & $\begin{array}{l}\text { Node selected with shorter } \\
\text { sink path \& higher } \\
\text { residual power. }\end{array}$ & $\begin{array}{l}\text { Sensor nodes with } \\
\text { large residual power are } \\
\text { more likely to become a } \\
\text { node of the non-leaf } \\
\text { tree. } \\
\text { The mean residual } \\
\text { energy of all live sensor } \\
\text { nodes gradually } \\
\text { decreases. } \\
\text { Lifetime of a network } \\
\text { increases linearly with } \\
\text { density of the network.. }\end{array}$ & $\begin{array}{l}\text { Network density not } \\
\text { considered at base } \\
\text { station. } \\
\text { Load } \\
\text { deficit. } \\
\text { If a child node } \\
\text { receives no message } \\
\text { for support or can't } \\
\text { switch to a new } \\
\text { parent, the node will } \\
\text { enter a danger state. }\end{array}$ \\
\hline Grid & $\begin{array}{l}\text { In- } \\
\text { network } \\
{[72]}\end{array}$ & $\begin{array}{l}\text { A data aggregator } \\
\text { collection per system. } \\
\text { Adding data for each grid. } \\
\text { Data aggregator based on } \\
\text { the signal strength by } \\
\text { chosen grid. }\end{array}$ & $\begin{array}{l}\text { Adapting dynamic } \\
\text { transition, and versatility } \\
\text { of events } \\
\text { That sensor node within } \\
\text { the grid interacts with } \\
\text { the nodes adjacent to it. }\end{array}$ & $\begin{array}{l}\text { Nodes in the same } \\
\text { system would not } \\
\text { interact among } \\
\text { themselves. } \\
\text { Data redundancy } \\
\\
\begin{array}{l}\text { Overhead } \\
\text { Aggregation head } \\
\text { selection }\end{array}\end{array}$ \\
\hline
\end{tabular}

\section{Comparative Precise Farming Techniques} Using Wireless Sensor Networks

Farmers, academics, \& technology manufacturers are working together to find more efficient solutions to complex agricultural problems to boost existing production and processes. Precision Agriculture is primarily based on tracking, measuring and responding to variability of crops intra- \& inter- field where agriculture acts as the
India's backbone \& approximately 70 per cent of the population of India relies on agriculture. Precision farming [45] is used to resolve numerous issues that arise in traditional farming, such as insufficient real-time data collection, limited spectrum of monitoring coverage, unrealistic standards of human resources etc. Precision farming that helped to drive agriculture into the world of computer based information 
using range of technologies developed for supporting farmers to gain control over farm operational management. Precision farming uses WSN in the management of soil moisture, temperature sensing, humidity monitoring, pressure sensing, $\mathrm{CO}_{2}$ sensing etc [47].

WSN-based precision farming infrastructure consists of monitoring nodes for the environment, communication systems, base stations, and internet connections \& hardwaresoftware application control networks. A WSN is an autonomous spatially distributed sensor which transmits its data to a main location over network [49]. The sensing circuits measure and convert the environmental conditions that surround the sensor into electrical signals that provide information about the detected objects or events that occur due to the proximity of the sensor when processed. While other types (ZigBee technology, HSCSD phone, GSM technology, HSCSD phone, GPRS phone, GPRS card phone, etc.) are capable of relaying these sensors' information to farmers.

Table 4 Comparison of Existing Technologies Used in Agriculture

\begin{tabular}{|l|l|l|l|l|l|l|l|l|}
\hline $\begin{array}{l}\text { Technolo } \\
\text { gy }\end{array}$ & $\begin{array}{l}\text { Communicat } \\
\text { ion } \\
\text { Technology }\end{array}$ & $\begin{array}{l}\text { Efficien } \\
\text { cy }\end{array}$ & Cost & Application & $\begin{array}{l}\text { Temperat } \\
\text { ure } \\
\text { Sensor }\end{array}$ & $\begin{array}{l}\text { Moistur } \\
\text { e } \\
\text { Sensor }\end{array}$ & $\begin{array}{l}\text { Humidi } \\
\text { ty } \\
\text { Sensor }\end{array}$ & $\begin{array}{l}\text { Soil } \\
\text { Senso } \\
\text { r }\end{array}$ \\
\hline $\begin{array}{l}\text { Wireless } \\
\text { Monitori } \\
\text { ng[60] }\end{array}$ & ZigBee & Less & Low & $\begin{array}{l}\text { Machine, } \\
\text { Monitoring, } \\
\text { Security etc. }\end{array}$ & No & Yes & Yes & No \\
\hline $\begin{array}{l}\text { Pervasiv } \\
\text { e } \\
\text { WSN } \\
\text { [61] }\end{array}$ & GSM, RFID & Ltd & High & $\begin{array}{l}\text { Communicati } \\
\text { on etc. }\end{array}$ & No & No & No & Yes \\
\hline $\begin{array}{l}\text { Using } \\
\text { WSN to } \\
\text { manage } \\
\text { PA [62] }\end{array}$ & RF & High & High & $\begin{array}{l}\text { Communicati } \\
\text { on, } \\
\text { Greenhouse } \\
\text { etc. }\end{array}$ & Yes & Yes & No & No \\
\hline $\begin{array}{l}\text { Irrigatio } \\
\text { n } \\
\text { Control } \\
\text { [63] }\end{array}$ & ZigBee & Less & Low & $\begin{array}{l}\text { Drip } \\
\text { Irrigation etc. }\end{array}$ & No & No & No & Yes \\
\hline $\begin{array}{l}\text { Monitori } \\
\text { ng of } \\
\text { WSN in } \\
\text { PA [64] }\end{array}$ & $\begin{array}{l}\text { ZigBee, } \\
\text { GPRS }\end{array}$ & Less & Low & $\begin{array}{l}\text { Communicati } \\
\text { on etc. }\end{array}$ & Yes & Yes & No & Yes \\
\hline $\begin{array}{l}\text { ZigBee } \\
\text { in } \\
\text { PA[65] }\end{array}$ & ZigBee & Less & Low & $\begin{array}{l}\text { ISM, Sensor } \\
\text { etc. }\end{array}$ & Yes & No & Yes & No \\
\hline
\end{tabular}

The WSN's data obtained at the central base station is usually processed in numerical data form, which allows anyone to track or administer WSN via Web browser. Sensor is a type of transducer that provides different forms of information, depending on the type of sensor it conducts. We compared several sensors used in existing technologies in Table 2.

\section{Related Work}

Soledad Escolar Díaz et al. 2011 proposed an innovative approach for tracking farm production processes focused on wireless sensor networks. The approach consists of a sequence of welldefined phases covering the entire life cycle of WSN agricultural monitoring applications. This 
theory consists of seven steps, each of which identifies a function, generates an input, generates an output, and performs a group of users; the process gathers the generic activities to be performed in that step, but also includes specific actions to be considered in accordance with different scenario requirements. The seven stages of the methodology form the base for WSN agricultural monitoring applications, which provide a stable foundation on which systems with considerable production gains and maintenance facilities can be built. On the basis of these advantages, we assume that our solution will contribute to the implementation of the WSN program in the agricultural sector.

Tyler W. Daviset al. 2012 interpret power characteristics of wireless sensor networking systems for the sap flow, soil moisture and soil water potential sensors. We address the reasons for achieving an extended battery life for individual wireless nodes while safeguarding adequacy and reliability in accurate data transmission sampling. First, they analyze how specific sensor characteristics, such as various types of flow sensors, can affect the sampling and transmission rate of nodes. We then examine the effect of a sensing attenuation on sap flow, soil water and soil moisture measurements due to the low battery energy. A basic regression model was used to correct sampled data on underpowered nodes, for both the sap flow and the soil water potential sensors. This effectively increases the battery life of motes by working below maximum power levels to collect data from wireless sensor networks effectively.

Xiaoqing Yu et al. 2013 addressed hybrid wireless sensor network architecture. It develops the requisite applications for integration and operating a hybrid WSN. Experiments were carried out using 50 percent sandy soil, 35 percent silt and 15 percent clay; it had a density of $1.5 \mathrm{~g} /$ $\mathrm{cm} 3$ and a density of $2.6 \mathrm{~cm}-3$.In addition, the deployment depth of the node influenced signal attenuation for the $433 \mathrm{MHz}$ link. This decides the optimal installation depth of nodes to communicate securely into an underground wireless sensor network. The network architecture was developed for the wireless hybrid sensor networks, and the deployment plan for the hybrid sensor network was presented. A wireless underground sensor network is analyzed according to design of the network and methods of deployment.

Andrew J. Phillips et al. 2014 a series of primary soil moisture dynamics monitoring recommendations for remote sensing integration and models including advanced on-site sensing technologies to allow less restrictive soil moisture measurement. In addition, it involves incorporation of in situ networks on a field scale with regional remote sensing monitoring \& this research is related to the creation of applications and web services to integrate multi-source data with model decision-support.

Tamoghna Ojha et al. 2015 presented a detailed review of State-of - the-art WSN delivery to specialized farming applications. Instead they introduced versions of the WSN - the terrestrial WSNs, and the underground WSNs. Then he stressed numerous WSN technologies and their ability to solve different agricultural problems. The consecutive parts of their paper described WSN's network and node architectures, the corresponding triggers, the classification by specific applications, the numerous wireless sensor nodes accessible and the various connectivity techniques followed by those nodes. Instead of using case studies, they discussed the latest WSN installations, globally and in India, for various agricultural applications. In the end, they explored the possibilities and issues of the current applications. They noted that low cost solution with features like autonomous operation needs little maintenance. Ultimately, innovative preplanning is required specifically for the success of these applications to address the problems in both 
global as well as LMICs (Low \& Middle Income Countries). Specifically, low cost solution requires low maintenance, with features such as autonomous operation. Ultimately, the performance of these applications includes creative pre-planning explicitly to overcome the problems in both global and LMICs.

Farzad Kiani 2016 concentrates on the topic of energy efficiency with various measures such as prolonging the network lifetime and rising the energy consumption of sensor nodes and increasing the durability of networks. Their suggested Procedure is composed of two stages. The sensors are placed into virtual layers during the first period (stage of network development). The second stage (data transmission) is linked to route exploration and data transfer, so that it is based on a virtual Classic-RBFS algorithm in energy-problem lake environments but in nonloadable environments, all nodes in each layer can be modeled as a random list, and then the task cycle process begins to handle them. This paper suggested an AR-RBFS-based routing protocol, to be implemented in two different scenarios on WSN. It is used to determine the power usage of the wireless sensor nodes and the efficiency of their packet transmission. The suggested technique can be extended to various applications, such as forestry, for both ecosystems.

James Gray et al. 2017 found the shortcomings of the existing framework for controlling the world and proposes a range of networking tools that can be utilized to enhance usability. Networking of environmental monitoring programs and the storage of recorded data is regarded. It also aims at designing and developing a software system to collect and archive collected environmental data from multiple farms. Simplified methods and methodologies for the software engineering were used to construct such a system. The main measures taken to complete the project included eliciting customer requests, updating the requirements, planning, executing the software and eventually checking it. The project results included a possible solution for enhancing the monitoring system for the environment, and an overview that indicated the application value. As suggested by this report, networking technologies are a viable option to reduce labor requirements and improve flexibility and efficiency by using networking, scripting, and database technology.

Maximilian Nicolae, Dan Popescu et al. (2018) They introduce in their paper a creative architecture for wireless sensor networks (WSNs) that can increase the performance of their precision farming (PA) systems. The authors argue that wider scale WSNs aren't automatically incorporated into PA. To this end, the paper explains the state of the art in WSNs that are used in PA, and proposes the proposed solution based on the conjectures established. The developed approach shows how small dimensional nodes can be without decreasing the communication range or the flexibility of the services. WSN is there to help and not to create overheads and issues. The communication protocol integrating the sleeping mechanism in simulation revealed that the proposed method might offer development in the WSN domain as WSNs would now qualify for widespread adoption in PA. On LoRa and LoRaWAN more and more of the WSN and IoT infrastructures are relying.

Devi Kala Rathinam. D et al. (2019) the wireless sensor nodes used for monitoring crops are mentioned in their paper, the instruments may be used for temperature detection, humidity and any other theft. This helps increase production in the agricultural sector. Automatic cycle decreases the human effort and allows the farmer to grow the agricultural land. The positioning of the fields may be transmitted using GPS. To render farming smart, other components such as sensor, Wi-Fi, camera and several other devices are used. All the captured information is stored in memory or cloud. WSN here is used to produce high yield and low cost crops. Nowadays, people do not 
know for agriculture. Human wireless sensor networks are used for effort reduction. The data is collected here by sensor nodes and sent to both farmers and field specialists. The smart phones are distributed using some additional information about the hardware and software. The farmer will run the cell phones from anywhere at any time. The initiative will also put together many producers, as well as the professional. This is best suited for agriculture-dependent countries such as India.

Table 5. Year-wise Distribution table of related work

\begin{tabular}{|c|c|c|c|}
\hline Year & Area & Devices / Technologies used & Result \\
\hline 2015 & $\begin{array}{l}\text { Agricultural WSN: State-of - the- } \\
\text { art in action and threats for the } \\
\text { future[48] }\end{array}$ & $\begin{array}{c}\text { Technologies for Wireless } \\
\text { communication -Modules ZigBee, } \\
\text { Wi-Max, Wi-Fi, GPRS/3G/4G, } \\
\text { Bluetooth and Various Sensors } \\
\text { (Soil Moisture Sensor, } \\
\text { Temperature Sensor and other } \\
\text { electronic devices). }\end{array}$ & $\begin{array}{l}\text { Increased cost, need } \\
\text { to improve } \\
\text { scalability. }\end{array}$ \\
\hline 2016 & $\begin{array}{l}\text { Decision-making support scheme } \\
\text { for rural irrigation management } \\
{[25]}\end{array}$ & $\begin{array}{l}\text { Machine learning methods used: } \\
\text { ANFIS (Adaptive Neural Fuzzy } \\
\text { Inference Systems) \& PLSR } \\
\text { (Partial Least Square Regression). }\end{array}$ & $\begin{array}{l}\text { Good performance, } \\
\text { accurate } \\
\text { information } \\
\text { prediction in the } \\
\text { field. }\end{array}$ \\
\hline 2017 & $\begin{array}{c}\text { Architecture of an IoT-enabled } \\
\text { agricultural precision platform } \\
\text { and ecological surveillance } \\
\text { [53] }\end{array}$ & $\begin{array}{l}\text { Data gathering sensors, Web portal } \\
\text { implementation using PHP and } \\
\text { laravel platform, Paas cloud } \\
\text { deployment, image capture drone. }\end{array}$ & $\begin{array}{c}\text { Precise and } \\
\text { frequent monitoring } \\
\text { of the livestock, } \\
\text { aquaculture and } \\
\text { monitoring of } \\
\text { different ecological } \\
\text { factors. }\end{array}$ \\
\hline 2017 & $\begin{array}{c}\text { A temperature-compensated } \\
\text { Smart Nitrate Monitor for } \\
\text { Farming } \\
{[54]}\end{array}$ & $\begin{array}{l}\text { Together with a planar type } \\
\text { interdigital sensor, } \\
\text { spectrophotometric method is used } \\
\text { for measuring soil nitrate levels; } \\
\text { Arduino Yun was used for the } \\
\text { development of sinusoidal volt, } \\
\text { and the use of soil and temperature } \\
\text { sensors. }\end{array}$ & $\begin{array}{l}\text { Linear, portable } \\
\text { through various } \\
\text { nitrate levels, this } \\
\text { approach improved } \\
\text { performance. }\end{array}$ \\
\hline 2017 & $\begin{array}{l}\text { Stable user authentication and } \\
\text { key agreement scheme for } \\
\text { tracking agriculture using } \\
\text { wireless sensor networks [66] }\end{array}$ & $\begin{array}{l}\text { Wireless IoT and BAN (Burrows- } \\
\text { Abadi-Needham) sensor networks } \\
\text { and AVISPA methods are used to } \\
\text { test protocols. }\end{array}$ & $\begin{array}{l}\text { Highly safe, cost } \\
\text { reduction }\end{array}$ \\
\hline 2017 & $\begin{array}{c}\text { Measuring Soil Macro Nutrients } \\
\text { For Smart Agriculture In Coconut } \\
\text { Growth } \\
{[55]}\end{array}$ & $\begin{array}{c}\text { Macro Nutrients including } \\
\text { Nitrogen }(\mathrm{N}), \text { Potassium }(\mathrm{P}) \& \\
\text { phosphorous }(\mathrm{K}) \text { are obtained } \\
\text { using the data } \\
\text { forwarding algorithm. }\end{array}$ & $\begin{array}{c}\text { Enhanced } \\
\text { Productivity, Cost } \\
\text { and time are saved, } \\
\text { as well. }\end{array}$ \\
\hline 2018 & $\begin{array}{l}\text { Wide WSN focused on Static } \\
\text { nodes \& mobile robots in } \\
\text { precision agriculture [56] }\end{array}$ & $\begin{array}{l}\text { Hybrid structure for WSN which } \\
\text { includes both mobile \& fixed } \\
\text { nodes (mounted on UAVs or AVs) }\end{array}$ & $\begin{array}{l}\text { Long range, cost of } \\
\text { longer time for } \\
\text { transmission }\end{array}$ \\
\hline
\end{tabular}




\begin{tabular}{|l|l|l|l|}
\hline 2019 & $\begin{array}{l}\text { An overview of energy efficiency } \\
\text { implemented in smart agriculture } \\
\text { in Wireless Sensor Networks } \\
\text { (WSNs) [67] }\end{array}$ & $\begin{array}{l}\text { WSN micro sensors are used with } \\
\text { global positioning system (GPS) } \\
\text { /sensor, Wi-Fi, cameras are used }\end{array}$ & $\begin{array}{l}\text { High } \\
\text { production with low } \\
\text { cost }\end{array}$ \\
\hline
\end{tabular}

\section{Research gap}

WSN's development has ignited new trends in agrarian science. Microelectromechanical system (MEMS) technologies include manufacturing inexpensive \& compact sensors. The device's omnipresent architecture along with cost-effective equipment, self-regulating sensor nodes \& scalability imply WSNs should be used for the automation of agriculture [5]. Nonetheless; there remain a range of open problems and limitations about the provision of WSNs for observing various agricultural climates. In current WSNbased agricultural applications, several of these problems and weaknesses are highlighted below, along with suggestions for how to deal with these.

i. Battery life and power consumption: A WSN contains three main components: microcontrollers, RF transceivers \& sensors. As sensor node battery has a small amount of energy, it is essential to ensure minimal power is consumed by the components of sensor node. This problem will be particularly mitigated by the energy consumption of the RF transceiver, which is more efficient than other sensor node components [67]. The first to deliver a smart energy efficient algorithm. To complete the second step, use the available energy collection techniques, such as solar cells.

ii. Range of communication: In spite of the wide variety of accessible agricultural habitats, WSNs are experiencing the effects of extreme environmental conditions [5]. The WSN protocol offers structures to tolerate the influence of environmental impacts induced by delays in the delivery of network data.

iii. Reliability: Agricultural monitoring systems based on various environmental sensors can also be used to track pollution, as well as climate conditions. Information on vital climatic conditions for advance investigations is obtained from remote locations by relevant agencies and farmers. Dangerous knowledge has to be answered quickly in the case of an emergency, which ensures that the high efficiency of data processing inside WSNs will be demonstrated [3].

iv. Security: Protection and safety of agricultural products are key issues. Protecting grain stores or fields from insects or rodent attacks is important. Such a question must be taken into account when preserving the standard of agricultural protection. Security and security may be accomplished without human intervention, relying on the study and processing of agricultural information in real time [59].

v. Heterogeneous sensors: The integration of heterogeneous wired and wireless sensors into interoperability of data knowledge databases raises problems within PA. Chen et al.[52] suggested a "web-service-enabled cyber-physical infrastructure" to address this issue. In the PA system, the conceptual network was able to integrate, store, capture and relay surveillance data from different physical sensors transmitted online.

\section{Conclusion\& Future Prospect}

This paper addressed a study of farm applications based on WSN \& various wireless protocols or technologies (Bluetooth, GPRS/3G/4G, WiFi, ZigBee, LoRa, and SigFox) have been compared. Also mentioned were the techniques or algorithms for energy efficiency. On the basis of the given classification and comparision, we demonstrate that important types of energy efficient and 
energy-harvesting techniques can be used in agriculture. Earlier research has also been investigated and contrasted with the study of current problems in farm applications based on the WSN and the research of optimum systems performance solutions. The state-of - the-art approaches to farm applications and the numerous controls, actuators, devices, IoT systems and technologies being studied are applied to the challenges and drawbacks to build requirements in future. The entire paper extends the scope of the study of precision farming. The successful use of the new crop yield technologies and the maximum benefit for farmers. This paper also provides a base for Precision Agriculture research for further work.

\section{References}

[1] Đoko Banđur, Branimir Jakšić, Miloš Banđur, Srđan Jović, 2019, “An analysis of energy efficiency in Wireless Sensor Networks (WSNs) applied in smart agriculture", Computers and Electronics in Agriculture ,Volume 156, Pages 500-507, ISSN 0168-1699.

[2] Díaz, S.E.; Pérez, J.C.; Mateos, A.C.; Marinescu, M.-C.; Guerra, B.B. 2011, “A novel methodology for the monitoring of the agricultural production process based on wireless sensor networks", Comput. Electron. Agric. 76, 252-265.

[3] Kim, Y.-D.; Yang, Y.-M.; Kang, W.-S.; Kim, D.-K., 2014, "On the design of beacon based wireless sensor network for agricultural emergency monitoring systems", Comput. Stand. Interfaces, 36, 288-299.

[4] Valente, J.; Sanz, D.; Barrientos, A.; Cerro, J.D.; Ribeiro, Á.; Rossi, C. , 2011, “An airground wireless sensor network for crop monitoring", Sensors 11, 6088-6108.

[5] Ojha, T.; Misra, S.; Raghuwanshi, N.S., 2015, "Wireless sensor networks for agriculture: The state-of-the-art in practice and future challenges", Comput. Electron. Agric. 118, 66-84.

[6] Tuna, G.; Gungor, V.C., 2016, "Energy harvesting and battery technologies for powering wireless sensor networks", In Industrial Wireless Sensor Networks; Kolavennu, S., Ed.; Woodhead Publishing: Sawston, UK; pp. 25-38.

[7] Tan, Y.K.; Panda, S.K., 2010, "Review of energy harvesting technologies for sustainable wireless sensor network", In Sustainable Wireless Sensor Networks, Seah, W., Ed.; InTech: Rijeka, Croatia, pp. $15-43$.

[8] Ilie-Ablachim, D.; Patru, G.C.; Florea, I.M.; Rosner, D., 2016, "Monitoring Device for Culture Substrate Growth Parameters for Precision Agriculture: Acronym: Monisen", In Proceedings of the 15th RoEduNet Conference: Networking in Education and Research, Bucharest, Romania, 7-9 September pp. 1-7.

[9] Cancela, J.; Fandiño, M.; Rey, B.; Martínez, E., 2015, "Automatic irrigation system based on dual crop coefficient, soil and plant water status for Vitis vinifera ( $\mathrm{cv}$ Godello and cv Mencia)", Agric. Water Manag. 151, 52-63.

[10] Rani, M.U.; Kamalesh, S., 2014, "Energy efficient fault tolerant topology scheme for precision agriculture using wireless sensor network". In Proceedings of the International Conference on Advanced Communication Control and Computing Technologies (ICACCCT), Ramanathapuram, India, 8-10 May; pp. 1208-1211.

[11] Rao, Y.; Jiang, Z.-H.; Lazarovitch, N. 2016, "Investigating signal propagation and strength distribution characteristics of wireless sensor networks in date palm orchards", Comput. Electron. Agric. 124, 107-120.

[12] Raheemah, A.; Sabri, N.; Salim, M.; Ehkan, P.; Ahmad, R.B., 2016, "New empirical 
path loss model for wireless sensor networks in mango greenhouses", Comput. Electron. Agric. 127, 553-560.

[13] Azaza, M.; Tanougast, C.; Fabrizio, E.; Mami, A., 2016, "Smart greenhouse fuzzy logic based control system enhanced with wireless data monitoring”, ISA Trans. 61, 297-307.

[14] Nadimi, E.S.; Jørgensen, R.N.; BlanesVidal, V.; Christensen, S., 2012, "Monitoring and classifying animal behavior using zigbee-based mobile ad hoc wireless sensor networks and artificial neural networks", Comput. Electron Agric. $82,44-54$.

[15] Kim, Y.; Evans, R.G.; Iversen,W.M., 2008, "Remote sensing and control of an irrigation system using a distributed wireless sensor network", IEEE Trans. Instrum. Meas. 57, 1379-1387.

[16] Kim, Y.; Evans, R., 2009, "Software design for wireless sensor-based site-specific irrigation", Comput. Electron. Agric. 66, 159-165.

[17] Gang, L.L.L., 2006, "Design of greenhouse environment monitoring and controlling system based on Bluetooth technology", Trans. Chin. Soc. Agric. Mach. 10, 97-100.

[18] Hong, G.-Z.; Hsieh, C.-L., 2016, "Application of integrated control strategy and bluetooth for irrigating romaine lettuce in greenhouse", IFAC-PapersOnLine 49, 381-386.

[19] Chung, S.-O.; Kang, S.-W.; Bae, K.-S.; Ryu, M.-J.; Kim, Y.-J., 2015, “The potential of remote monitoring and control of protected crop production environment using mobile phone under $3 \mathrm{G}$ and $\mathrm{Wi}-\mathrm{Fi}$ communication conditions", Eng. Agric. Environ. Food 8, 251-256.

[20] Mohapatra, A.G.; Lenka, S.K., 2016, "Neural network pattern classification and weather dependent fuzzy logic model for irrigation control in WSN based precision agriculture", Procedia Comput. Sci. 78, 499-506.

[21] Mendez, G.R.; Mukhopadhyay, S.C., 2013, "A Wi-Fi based smart wireless sensor network for an agricultural environment", In Wireless Sensor Networks and Ecological Monitoring, Springer: Berlin/Heidelberg, Germany, pp. 247-268.

[22] Nesa Sudha, M.; Valarmathi, M.L.; Babu, A.S., 2011, "Energy efficient data transmission in automatic irrigation system using wireless sensor networks", Comput. Electron. Agric. 78, 215-221.

[23] Gutiérrez, J.; Villa-Medina, J.F.; NietoGaribay, A.; Porta-Gándara, M.Á., 2014, "Automated irrigation system using a wireless sensor network and gprs module", IEEE Trans. Instrum. Meas. 63, 166-176.

[24] Zhang, R.; Chen, L.; Guo, J.; Meng, Z.; Xu, G., 2010, "An energy-efficient wireless sensor network used for farmlandsoil moisture monitoring", In Proceedings of the IET Conference on Wireless Sensor Network, Beijing, China,15-17 November pp. 2-6.

[25] Navarro-Hellín, H.; Torres-Sánchez, R.; Soto-Valles, F.; Albaladejo-Pérez, C.; López-Riquelme, J.;Domingo-Miguel, R., 2015, "A wireless sensors architecture for efficient irrigation water management", Agric.Water Manag. 151, 64-74.

[26] Pitì, A.; Verticale, G.; Rottondi, C.; Capone, A.; Lo Schiavo, L., 2017, "The role of smart meters in enabling real-time energy services for households: The Italian case", Energies, 10, 199. Sensors 17, 1781 39 of 45

[27] Gil-Lebrero, S.; Quiles-Latorre, F.J.; OrtizLópez, M.; Sánchez-Ruiz, V.; GámizLópez, V.; Luna-Rodríguez, J.J., 2016, "Honey bee colonies remote monitoring system", Sensors 17, 55.

[28] Llaria, A.; Terrasson, G.; Arregui, H.; Hacala, A., 2015, "Geolocation and Monitoring Platform for Extensive Farming 
in Mountain Pastures", In Proceedings of the IEEE International Conference on Industrial Technology (ICIT), Seville, Spain, 17-19 March pp. 2420-2425.

[29] Terrasson, G.; Llaria, A.; Marra, A.; Voaden, S., 2016, "Accelerometer based solution for precision livestock farming: Geolocation enhancement and animal activity identification", In IOP Conference Series: Materials Science and Engineering; IOP Publishing: Bristol, UK.

[30] Rault, T.; Bouabdallah, A.; Challal, Y., 2014, "Energy efficiency in wireless sensor networks: A top-down survey", Comput. Netw. 67, 104-122.

[31] Matese, A.; Vaccari, F.P.; Tomasi, D.; Di Gennaro, S.F.; Primicerio, J.; Sabatini, F.; Guidoni, S., 2013, "Crossvit: Enhancing canopy monitoring management practices in viticulture", Sensors 13, 7652-7667.

[32] Azpilicueta, L.; López-Iturri, P.; Aguirre, E.; Mateo, I.; Astrain, J.J.; Villadangos, J.; Falcone, F., 2014, "Analysis of radiowave propagation for ISM $2.4 \mathrm{GHz}$ wireless sensor networks in inhomogeneous vegetation environments", Sensors 14, 23650-23672.

[33] Marques, G.; Pitarma, R., 2016, “An indoor monitoring system for ambient assisted living based on internet of things architecture", Int. J. Environ. Res. Public Health 13, 1152.

[34] Malaver, A.; Motta, N.; Corke, P.; Gonzalez, F. Development and integration of a solar powered unmanned aerial vehicle and a wireless sensor network to monitor greenhouse gases. Sensors 2015, 15, 40724096.

[35] Aquino-Santos, R.; González-Potes, A.; Edwards-Block, A.; Virgen-Ortiz, R.A., 2011, "Developing a new wirelesssensor network platform and its application in precision agriculture", Sensors 11, 11921211.
[36] Adelantado, F.; Vilajosana, X.; Tuset-Peiro, P.; Martinez, B.; Melia, J., 2016, "Understanding the limits of LoRaWAN", arXiv preprint, arXiv:1607.08011.

[37] Kirichek, R.; Kulik, V., 2016, "Long-Range Data Transmission on Flying Ubiquitous Sensor Networks (FUSN) by Using Lpwan Protocols", In Proceedings of the International Conference on Distributed Computerand Communication Networks, Moscow, Russia, 21-25 November Springer: Cham, Switzerland;pp. 442-453.

[38] Ali, A.; Shah, G.A.; Farooq, M.O.; Ghani, U., 2017, "Technologies and challenges in developing machine-to-machine applications: A survey", J. Netw. Comput. Appl. 83, 124-139.

[39] Hwang, Jeonghwan \& Shin, Changsun \& Yoe, Hyun., 2010, "Study on an Agricultural Environment Monitoring Server System Using Wireless Sensor Networks". Sensors (Basel, Switzerland).

[40] Soledad Escolar Díaz, Jesús Carretero Pérez, Alejandro Calderón Mateos, MariaCristina Marinescu, Borja Bergua Guerra, 2011, "A novel methodology for the monitoring of the agricultural production process based on wireless sensor networks", Computers and Electronics in Agriculture, Volume 76, Issue 2, Pages 252-265,

[41] T. W. Davis, X. Liang, C. Kuo and Y. Liang, "Analysis of Power Characteristics for Sap Flow, Soil Moisture, and Soil Water Potential Sensors in Wireless Sensor Networking Systems," in IEEE Sensors Journal, vol. 12, no. 6, pp. 1933-1945, June 2012.

[42] Xiaoqing $\mathrm{Yu}$, Pute $\mathrm{Wu}$, Wenting Han, Zenglin Zhang, 2013, "A survey on wireless sensor network infrastructure for agriculture", Computer Standards \& Interfaces, Volume 35, Issue 1, ,Pages 5964, ISSN 0920-5489. 
[43] Andrew J. Phillips, Nathaniel K. Newlands, Steve H.L. Liang, Benjamin H. Ellert, 2014, "Integrated sensing of soil moisture at the field-scale: Measuring, modeling and sharing for improved agricultural decision support", Computers and Electronics in Agriculture, Volume 107, Pages 73-88, ISSN 0168-1699.

[44] Tamoghna Ojha, Sudip Misra, Narendra Singh Raghuwanshi, 2015, "Wireless sensor networks for agriculture: The stateof-the-art in practice and future challenges", Computers and Electronics in Agriculture, Volume 118, Pages 6684,ISSN 0168-1699

[45] Blackmore, S., 1994, "Precision farming: an introduction". Outlook on agriculture, 23(4), pp.275-280.

[46] James Gray, Thomas M. Banhazi, Alexander A. Kist, 2017, "Wireless data management system for environmental monitoring in livestock buildings", Information Processing in Agriculture, Volume 4, Issue 1, Pages 1-17,ISSN 22143173

[47] Nicolae, Maximilian \& Popescu, Dan \& Merezeanu, Daniel Marian \& Ichim, Loretta., 2019, "Large Scale Wireless Sensor Networks Based on Fixed Nodes and Mobile Robots in Precision Agriculture", Proceedings of the 27th International Conference on Robotics in Alpe-Adria Danube Region (RAAD 2018).

[48] D. D. K. Rathinam, D. Surendran, A. Shilpa, A. S. Grace and J. Sherin, 2019, "Modern Agriculture Using Wireless Sensor Network (WSN)," 5th International Conference on Advanced Computing \& Communication Systems (ICACCS), Coimbatore, India, 2019, pp. 515-519.

[49] Tomo Popović, Nedeljko Latinović, Ana Pešić, Žarko Zečević, Božo Krstajić, Slobodan Djukanović, 2017, “Architecting an IoT-enabled platform for precision agriculture and ecological monitoring: A case study", Computers and Electronics in Agriculture, Volume 140 ,Pages 255265,ISSN 0168-1699

[50] Azaza, M., Tanougast, C., Fabrizio, E. and Mami, A., 2016, "Smart greenhouse fuzzy logic based control system enhanced with wireless data monitoring”, ISA transactions, 61, pp.297-307.

[51] Kim, Y. and Evans, R.G., 2009, "Software design for wireless sensor-based sitespecific irrigation", Computers and Electronics in Agriculture, 66(2), pp.159165.

[52] Nicolae M., Popescu D., Merezeanu D., Ichim L., 2019, "Large Scale Wireless Sensor Networks Based on Fixed Nodes and Mobile Robots in Precision Agriculture", Advances in Service and Industrial Robotics. Springer, Cham, vol 67.

[53] Ramesh, R., \& Varshney, P. K., 2006, "Data aggregation techniques in sensor networks: A survey”. Electrical Engineering and Computer Science. Paper 22. http://surface.syr.edu/eecs/22.

[54] Fan, K. W., Liu, S., \& Sinha, P., 2007, "Structure-free data aggregation in sensor networks". IEEE Transactions on Mobile Computing, 6(8), 929-942.

[55] Heinzelman, W.R., Kulik, J. and Balakrishnan, H., 1999, "Adaptive protocols for information dissemination in wireless sensor networks". In Proceedings of the 5th annual ACM/IEEE international conference on Mobile computing and networking (pp. 174-185). ACM., August.

[56] N. Boughanmi, M. Esseghir, L. MerghemBoulahia, and L. Khoukhi, 2012, "Energy efficient aggregation in wireless sensor networks," in Proc.ICAIT, pp. 264-273.

[57] A. Sardouk, R. Rahim-Amoud, L. Merghem-Boulahia, and D. Gaiti, 2009, "A Multi-criteria data aggregation scheme for WSN," in Proc. WiMob.Marrakech. 
[58] S. Lindsey, C. Raghavendra, and K.M. Sivalingam, 2002, "Data gathering algorithms in sensor networks using energy metrics," IEEE Trans. Parallel and Distributed Systems, vol. 13, no. 9, September pp. 924-935.

[59] Vaidhyanathan, K., Sur, S., Narravula, S., \& Sinha, P., 2004, "Data aggregation techniques sensor networks", Technical report, OSU-CISRC-11/04-TR60, Ohio State University.

[60] Chavan, C.H. and Karande, P.V., 2014, "Wireless monitoring of soil moisture, temperature \& humidity using zigbee in agriculture", International Journal of Engineering Trends and Technology (IJETT), 11(10), pp.493-497.

[61] Wark, T., Corke, P., Sikka, P., Klingbeil, L., Guo, Y., Crossman, C., Valencia, P., Swain, D. and Bishop-Hurley, G., 2007, "Transforming agriculture through pervasive wireless sensor networks", IEEE Pervasive Computing, 6(2), pp.50-57.

[62] Hussain, R., Sahgal, J.L. and Riyaj, M., 2013, "Control of irrigation automatically by using wireless sensor network", International Journal of Soft Computing and Engineering (IJSCE)ISSN: 2231-2307, Volume-3, Issue-1, March.

[63] Chaudhary, D.D., Nayse, S.P. and Waghmare, L.M., 2011, "Application of wireless sensor networks for greenhouse parameter control in precision agriculture". International Journal of Wireless \& Mobile Networks (IJWMN), 3(1), pp.140-149.

[64] Kalra, A., Chechi, R. and Khanna, R., 2010, "Role of Zigbee Technology in agriculture sector". In National Conf. on Computational Instrumentation NCCI 2010 CSIO (19-20 March 2010 Chandigarh, India) (p. 151).

[65] Sinduja, R.M. and Sowmya, S., 2013, "Monitoring of rice crops using GPRS and wireless sensors for efficient use of water and electricity". Int. J. Appl. Innov. Eng. Manag, 2(9), pp.269-274.

[66] Ali, R., Pal, A.K., Kumari, S., Karuppiah, M. and Conti, M., 2018, "A secure user authentication and key-agreement scheme using wireless sensor networks for agriculture monitoring". Future Generation Computer Systems, 84, pp.200-215.

[67] Surendran, D., Shilpa, A. and Sherin, J., 2019, "Modern Agriculture Using Wireless Sensor Network (WSN)", In 2019 5th International Conference on Advanced Computing \& Communication Systems (ICACCS) (pp. 515-519). IEEE. March.

[68] Jawad, H.M., Nordin, R., Gharghan, S.K., Jawad, A.M. and Ismail, M., 2017, "Energy-efficient wireless sensor networks for precision agriculture: A review", Sensors, 17(8), p.1781.

[69] Heinzelman, W.B., Chandrakasan, A.P. and Balakrishnan, H., 2002, "An applicationspecific protocol architecture for wireless microsensor networks", IEEE Transactions on wireless communications, 1(4), pp.660670.

[70] Lindsey, S., Raghavendra, C. and Sivalingam, K.M., 2002, "Data gathering algorithms in sensor networks using energy metrics", IEEE Transactions on parallel and distributed systems, 13(9), pp.924-935.

[71] Ding, M., Cheng, X. and Xue, G., 2003, "Aggregation tree construction in sensor networks". In 2003 IEEE 58th Vehicular Technology Conference. VTC 2003-Fall (IEEE Cat. No. 03CH37484) (Vol. 4, pp. 2168-2172). IEEE. October.

[72] Vaidyanathan, K., Sur, S., Narravula, S. and Sinha, P., 2004, "Data aggregation techniques in sensor networks". Osu-cisrc11/04-tr60, The Ohio State University.

[73] Kulik, J., Heinzelman, W. and Balakrishnan, H., 2002, "Negotiation-based protocols for disseminating information in wireless sensor networks", Wireless networks, 8(2-3), pp.169-185. 
[74] Fan, K.W., Liu, S. and Sinha, P., 2007, "Structure-free data aggregation in sensor networks", IEEE transactions on mobile computing, 6(8), pp.929-942.

[75] Chao, C.M. and Hsiao, T.Y., 2009, "Design of structure-free and energy-balanced data aggregation in wireless sensor networks", 11th IEEE International Conference on High Performance Computing and Communications (pp. 222-229). IEEE. June.

[76] Sardouk, A., Mansouri, M., MerghemBoulahia, L., Gaiti, D. and Rahim-Amoud, R., 2010, "Multi-agent system based wireless sensor network for crisis management", IEEE Global Telecommunications Conference GLOBECOM (pp. 1-6). IEEE. December. 